Marquette University

e-Publications@Marquette

Biomedical Engineering Faculty Research and

Publications

Biomedical Engineering, Department of

2017

\title{
Lung Injury Pathways: Adenosine Receptor 2B Signaling Limits Development of Ischemic Bronchiolitis Obliterans Organizing Pneumonia
}

\author{
John C. Densmore \\ Medical College of Wisconsin \\ Terry R. Schaid \\ Medical College of Wisconsin \\ Paul M. Jeziorczak \\ Medical College of Wisconsin \\ Meetha Medhora \\ Medical College of Wisconsin \\ Said H. Audi \\ Marquette University, said.audi@marquette.edu
}

See next page for additional authors

Follow this and additional works at: https://epublications.marquette.edu/bioengin_fac

Part of the Biomedical Engineering and Bioengineering Commons

\section{Recommended Citation}

Densmore, John C.; Schaid, Terry R.; Jeziorczak, Paul M.; Medhora, Meetha; Audi, Said H.; Nayak, Shraddha; Auchampach, John; Dwinell, Melinda R.; Geurts, Aron M.; and Jacobs, Elizabeth R., "Lung Injury Pathways: Adenosine Receptor 2B Signaling Limits Development of Ischemic Bronchiolitis Obliterans Organizing Pneumonia" (2017). Biomedical Engineering Faculty Research and Publications. 538.

https://epublications.marquette.edu/bioengin_fac/538 


\section{Authors}

John C. Densmore, Terry R. Schaid, Paul M. Jeziorczak, Meetha Medhora, Said H. Audi, Shraddha Nayak, John Auchampach, Melinda R. Dwinell, Aron M. Geurts, and Elizabeth R. Jacobs 
Marquette University

e-Publications@Marquette

\section{Biomedical Engineering Faculty Research and Publications/College of} Engineering

This paper is NOT THE PUBLISHED VERSION; but the author's final, peer-reviewed manuscript. The published version may be accessed by following the link in the citation below.

Experimental Lung Research, Vol. 43, No. 1 (2017): 38-48. DOI. This article is (C) Taylor \& Francis and permission has been granted for this version to appear in e-Publications@Marquette. Taylor \& Francis does not grant permission for this article to be further copied/distributed or hosted elsewhere without the express permission from Taylor \& Francis.

\section{Lung Injury Pathways: Adenosine Receptor 2B Signaling Limits Development of Ischemic Bronchiolitis Obliterans Organizing Pneumonia}

John C. Densmore

Children's Research Institute, Milwaukee, Wisconsin

Clinical and Translational Science Institute, Milwaukee, Wisconsin

Medical College of Wisconsin, Milwaukee, Wisconsin

Terry R. Schaid

Medical College of Wisconsin, Milwaukee, Wisconsin

Paul M. Jeziorczak

Children's Research Institute, Milwaukee, Wisconsin

Medical College of Wisconsin, Milwaukee, Wisconsin

Meetha Medhora

Medical College of Wisconsin, Milwaukee, Wisconsin 


\section{Said Audi}

Marquette University, Milwaukee, Wisconsin

\section{Shraddha Nayak}

Medical College of Wisconsin, Milwaukee, Wisconsin

John Auchampach

Medical College of Wisconsin, Milwaukee, Wisconsin

\section{Melinda R. Dwinell}

Medical College of Wisconsin, Milwaukee, Wisconsin

\section{Aron M. Geurts}

Medical College of Wisconsin, Milwaukee, Wisconsin

\section{Elizabeth R. Jacobs}

Clinical and Translational Science Institute, Milwaukee, Wisconsin

Medical College of Wisconsin, Milwaukee, Wisconsin

Clement J. Zablocki Veterans Affairs Medical Center, Milwaukee

\section{ABSTRACT}

Purpose/Aim of the Study: Adenosine signaling was studied in bronchiolitis obliterans organizing pneumonia (BOOP) resulting from unilateral lung ischemia. Materials and Methods: Ischemia was achieved by either left main pulmonary artery or complete hilar ligation. Sprague-Dawley (SD) rats, Dahl salt sensitive (SS) rats and SS mutant rat strains containing a mutation in the A2B adenosine receptor gene (Adora2b)were studied. Adenosine concentrationswere measured in bronchoalveolar lavage (BAL) by HPLC. A2A (A2AAR) and A2B adenosine receptor (A2BAR) mRNA and protein were quantified. Results: Twenty-four hours after unilateral PA ligation, $B A L$ adenosine concentrations from ischemic lungs were increased relative to contralateral lungs in SD rats. A2BAR mRNA and protein concentrations were increased after PA ligation while miR27a, a negatively regulatingmicroRNA, was decreased in ischemic lungs. A2AAR mRNA and protein concentrations remained unchanged following ischemia. A2BAR protein was increased in PA ligated lungs of SS rats after 7 days, and $4 \mathrm{~h}$ after complete hilar ligation in SD rats. SS-Adora2b mutants showed a greater extent of BOOP relative to SS rats, and greater inflammatory changes. Conclusion: IncreasedA2BAR and adenosine following unilateral lung ischemia as well as more BOOP in A2BAR mutant rats implicate a protective role for A2BAR signaling in coun

\section{Keywords:}

$\mathrm{A} 2 \mathrm{~B}$ adenosine receptor; bronchiolitis obliterans organizing pneumonia; lung ischemia; lung transplanttering ischemic lung injury.

\section{Introduction}

Lung transplantation is the final option for patients suffering from end-stage lung disease. The efficacy of 2000 yearly transplants in the United States is severely limited by graft availability, preoperative function, and a $50 \%$ postoperative failure rate within 5 years. [ 1] Bronchiolitis obliterans (BO), a pathologic condition in which small airways become irreversibly obstructed by granulation tissue and fibrosis, is the major cause of morbidity and mortality resulting from lung transplantation. [ 1], [ 2] As a harbinger of $\mathrm{BO}$, bronchiolitis obliterans organizing pneumonia (BOOP) occurs early postoperatively (weeks to months) and is associated with a doubled risk of subsequent BO and graft failure.[ 3], [ 4] Ischemia/reperfusion (I/R) is a major risk factor for all post-transplant problems, including BOOP.[ 5] In order to detect and understand the early ischemic mechanisms inducing BOOP, we developed a rat model of unilateral lung ischemia whereby the left pulmonary artery is ligated in situ. This 
provides a contralateral control lung for comparison. This model completely avoids immunomodulation and maintains ventilation to both lungs. [ 6 ] In the present work, we explore the role of adenosine signaling in this injury response.

Pulmonary I/R increases adenosine production, with some studies reporting a proinflammatory role for $A_{2 B}$ adenosine receptor ( $\left.A_{2 B} A R\right)$ engagement in the transplanted lung.[ 7]], [ ㅇ] , [ $\underline{9}$ ] However, others describe $A_{2 B} A R$ conferring protection against lipopolysaccharide- or mechanical ventilation-induced direct lung injury.[10], [11], [12] The goal of this study was to examine the role of $A_{2 B} A R$ signaling promoting postischemic $B O O P$. The studies presented utilize a novel rat $A_{2 B} A R$ mutant, $A_{2 B} A R$ mRNA lung levels, $A_{2 B} A R$ lung protein expression, and translation-regulating miRNA lung levels to correlate $A_{2 B} A R$ function with histopathologic changes seen in ischemic BOOP. We report data from three strains of rats, including Sprague Dawley rats, an $A_{2 B} A R$ mutant, and the background strain for the $A 2 b$ mutant, SS rats. These three strains permit conclusions regarding the role of $A 2 b$ receptors in rodents with two significantly different genetic backgrounds, thus enhancing the translational implications to humans with widely variable genetic makeups.

There are currently three known miRNA sequences that regulate $A_{2 B} A R$ expression: miR27b, miR128a, and miR128b. [13], [14], [15] All three have been implicated in $A_{2 B} A R$ in vitro signaling (e.g., B-lymphocyte differentiation and 3T3-PKD-1 cell differentiation).[13], [15] Given the negative regulation of $A_{2 B} A R$ in murine colitis, we focused upon the role of miR27b and miR128a in this model.[14]

Our data provide evidence that adenosine release and activation of $A_{2 B} A R s$ are protective responses that limit the development of BOOP, and hence BO.

\section{Materials and methods}

antibodies for $A_{2 A} A R$ and $A_{2 B} A R$ were purchased from Alomone labs ( $A_{2 B} A R$ Cat\# AAR-003, $A_{2 A} A R$ Cat\# AAR-002). Adenosine for standards was obtained from Sigma (Cat\#A9251). $\beta$-actin antibody was also obtained from Sigma (Cat\#A2228).

Sequence specific primers for miRNA were obtained from Exiqon. Target sequences follow:

- miR-128-3p: UCACAGUGAACCGGUCUCUUU Product\# 205677

- miR-27a-3p: UUCACAGUGGCUAAGUUCCGC Product\#204764

- miR-27b-3p: UUCACAGUGGCUAAGUUCUGC Product\# 204782

- miR-191a-5p: CAACGGAAUCCCAAAAGCAGCUG Product \#204306).

- mRNA primers were obtained from Integrated DNA Technology with following sequences:

- $\quad A_{2 \mathrm{~B}}$ AR forward: GCGGCACCTTAGCGGCTGTC (Product\#117239370)

- $\quad A_{2 B}$ AR reverse: TACCTGAGCGGGACGCGAAT (Product\#117239371)

- A $2 A A R_{A}$ forward: CCATGCTGGGCTGGAACA (Product\# 117239368)

- A $2 A_{2 A R}$ reverse: GAAGGGGCAGTAACACGA (Product \#117239369)

Animal models: AdorA2b mutants. All animal procedures including the generation of the $A_{2 B} A R$ mutant model, breeding, and phenotypic characterization were performed at the Medical College of Wisconsin using protocols approved by the Institutional Animal Care and Use Committee and in compliance with the National Research 
Council's Guide for the Care and Use of Laboratory Animals. Zinc-Finger Nuclease (ZFN) constructs specific for rat AdorA2BA were designed, assembled, and validated by Sigma-Aldrich, to target the sequence

AACTACTTTCTGGTGTccctgGCGACGGCGGACGTGGCT within the first exon of AdorA2BA, where each member of heterodimeric ZFN pair binds to the underlined sequence on opposite strands. mRNA encoding the AdorA2BA ZFN was injected into SS/JrHsdMcwi (SS) rat embryos, as described previously.[16], [17] Mutant founders were identified using the primers $A_{2 B} A R \_F$ : ACACAACCCCGGTAGAGGA and $A_{2 B} A R \_R$ : GATGGAGCTCTGTGTGAGCA.

A founder harboring genomic deletion was identified and validated by Sanger sequencing (Figure 1). A mutant founder was backcrossed to the parental SS strain and heterozygous animals from subsequent generations were intercrossed in order to generate homozygous mutant animals and were used for all reported studies. This strain is designated as SS-Adora2b. Parental SS rats were used as genetic background controls.

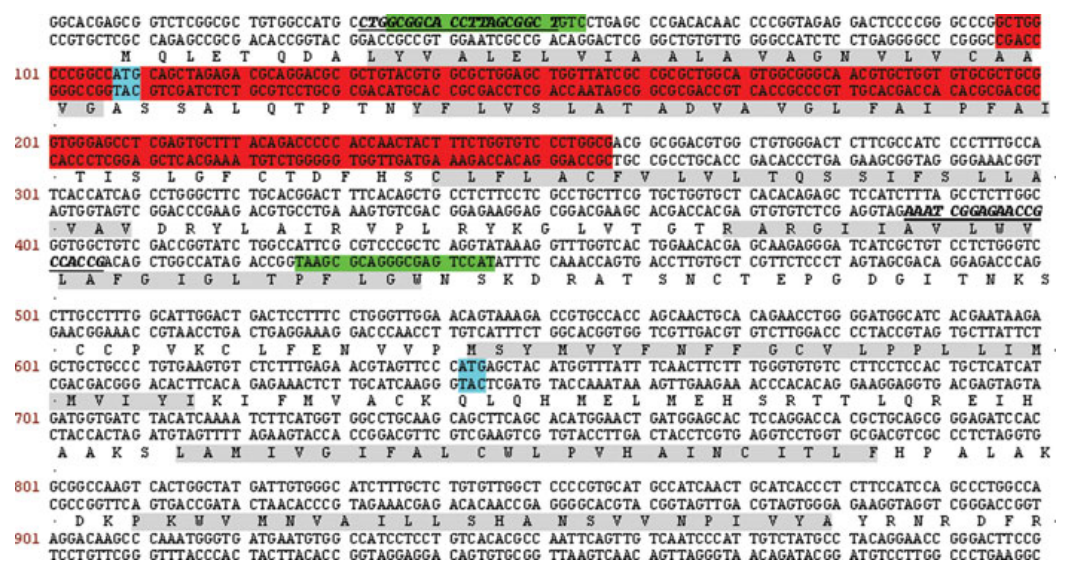

Graph: Figure 1. cDNA sequence of the A2BAR highlighting the Adora2b mutation, which caused an in-frame deletion. The red region denotes the mutated region, which resulted in deletion of the start codon (blue). The next available start codon is highlighted in blue. This mutated strain is predicted to express a truncated form of the A2BAR lacking the amino terminus, intracellular loops 1 and 2, extracellular loops 1 and 2, and the first 4 transmembrane segments. The green highlights indicate the primer set used for genotyping. Transmembrane regions are highlighted in light grey for easy identification of these areas deleted.

Surgical procedures: Male SD (Harlan Labs), SS or $A_{2 B} A R$ mutant rats (200-400 gm) were used for the experiments. To create unilateral ischemia without compromise of airflow or reperfusion, we used a left anterior thoracotomy to complete an occlusive slip knot tie over the left main pulmonary artery under general anesthesia using isoflurane (2\%), as we previously reported.[ 6] In brief, the left main pulmonary artery was identified on the superior aspect of the left mainstem bronchus and then dissected free from the bronchus. A 6O suture was passed around the left main pulmonary artery and tied.[ 6] Rats were allowed to recover from surgery, administered carprofen ( $5 \mathrm{mg} / \mathrm{kg}$ b.i.d. for 3 days) for analgesia and studied 1-7 days later.

In selected rats where indicated in the text, a second model of unilateral lung ischemia characterized by increased myeloperoxidase as we previously reported with PA and airway ischemia and reperfusion was employed.[18] A midline incision was made and the chest opened to access the left hilum. The left pulmonary artery, vein, and bronchus were stripped of connective tissue and then occluded with a microvascular clamp to induce ischemia. After 60 minutes, the clamp was removed to allow spontaneous reperfusion and reinitiation of lung ventilation. Lung tissue was harvested three hours after reperfusion.

Adenosine BAL measurements: Adenosine was measured by adaptation of methods described by Driver et al.[19] Twenty four hours after left pulmonary artery ligation (see earlier text), Sprague-Dawley rats were anesthetized with $2 \%$ isoflurane, intubated, and subjected to thoracotomy via a midline incision. The heart and 
lungs were removed from the chest en block, after which the left and right lungs were lavaged separately two times with $3.0 \mathrm{~mL}$ of PBS $\left(4^{\circ} \mathrm{C}\right)$ containing the adenosine deaminase inhibitor erythro-9-(2-hydroxy-3nonyl)adenine hydrochloride (EHNA, $2.5 \mu \mathrm{M})$ and the nucleotide transport inhibitor dipyridamole $(250 \mu \mathrm{M})$ (stopping solutions). In the case of control rats, lavage fluid $(5.0 \mathrm{~mL})$ was collected from both lungs. BAL fluid was centrifuged $\left(1000 \mathrm{~g}\right.$ for $10 \mathrm{~min}$ at $4^{\circ} \mathrm{C}$ ) and then passed through a $0.2 \mu$ filter to remove cellular debris.

To determine the range and sensitivity of our assay as well as potential sources of loss with filtration, centrifugation or freezing, adenosine (cat\# A9251 Sigma) was added to lavage fluid from an independent group of control rats to final concentrations of 2,10 , and $50 \mu \mathrm{M}$ above endogenous adenosine levels either before or after centrifugation and filtration.

Briefly, an Agilent $1100 \mathrm{HPLC}$ system was used and the samples $(100 \mu \mathrm{L})$ were injected into Kinetex $\mathrm{C}_{18}$ columns (Phenomenex, $100 \mathrm{~mm} \times 4.6 \mathrm{~mm}, 2.6 \mu \mathrm{m}$ ) equipped with a guard column and equilibrated with an aqueous solution of $\mathrm{KH}_{2} \mathrm{PO}_{4}(12.5 \mathrm{mM})$ containing $7.5 \%$ methanol. Isocratic elution of adenosine was achieved using the equilibration buffer at a flow rate of $1.4 \mathrm{ml} / \mathrm{min}$. The retention time of adenosine was $4.2 \mathrm{~min}$ by UV detection at $260 \mathrm{~nm}$. Peak area at $260 \mathrm{~nm}$ was used for quantification.

RNA studies: Total RNA from $\sim 100 \mathrm{mg}$ of right and left lung tissues were extracted with Trizol reagent (Cat\# 15596-026, Invitrogen, USA), according to the manufacturer's instructions. The concentration and purity of RNA were determined by a Nanodrop spectrophotometer.

Quantitative ${ }^{\text {Table }}{ }^{1}$ real time PCR. Synthesis of CDNA was performed using the miRCURY LNA Universal RT microRNA PCR kit (Cat\# 203301,Exiqon). A total of $100 \mathrm{ng}$ of total RNA was used for reverse transcription with polyT-tagged universal primer. Briefly, the tubes were incubated for $60 \mathrm{~min}$ at $42^{\circ} \mathrm{C}$, followed by heatinactivation of the reverse transcriptase enzyme for $5 \mathrm{~min}$ at $95^{\circ} \mathrm{C}$. Real-time $P C R$ was performed with $A_{2 A} A R$, $A_{2 B} A R$ and GAPDH (internal control) primers using recommended annealing temperatures for each primer set (IDT). For miRNA, real-time PCR was performed with miR-27a-3p (cat\# 204764), miR-27b-3p (cat\# 204782), and miR-128-3p(cat\# 295677) LNA primers (Exiqon), as well as SYBR Green master mix (Cat\# 203403 Exiqon). MiR191a-5p (cat \# 204306) was used as an internal control along with UniSP6 provided with the cDNA kit to account for efficiency of reverse transcription for miRNA analyses. PCR was carried out according to the manufacturer's instructions (Cat\# 203301, Exiqon) using a Bio-Rad icycler (Model CFX 96 Real time system). The following cycling conditions were employed for miRNA: $95^{\circ} \mathrm{C}$ for $10 \mathrm{~min}$, followed by 40 cycles of $95^{\circ} \mathrm{C}$ for $10 \mathrm{~s}$, and $60^{\circ} \mathrm{C}$ for $1 \mathrm{~min}$. The expression level of mRNA in each sample was normalized to GAPDH and miRNA to either miR-191a$5 p$ or to UniSP6. Then, relative expression levels in right and left lung samples were calculated using the CT values for the RNA of interest by using $2^{-\Delta \Delta C T}$ method.

Western immunoblotting of $A_{2 A} A R$ and $A_{2 B} A R$ : Western blot analysis was performed as described previously.[18] Briefly, whole lung homogenates in a buffer supplemented with protease inhibitor cocktail were centrifuged for $10 \mathrm{~min}$ at $20,000 \mathrm{~g}$. Blots were developed with a primary antibody to $A_{2 A} A R, A_{2 B} A R$ or $\beta$-actin (Sigma \#A2228) and matched secondary antibodies conjugated to horseradish peroxidase. ECL detection reagent (Pierce \# 32106) was used for visualization. The relative densities of protein bands were compared in images scanned with an Alpha Image 220 Analysis System, with $\beta$-actin used to correct for protein loading. Bands at $\sim 48$ and $37 \mathrm{kDa}$ were observed in our immunoblots. The band just smaller than $50 \mathrm{kDa}$ is consistent with immunospecific band identified by this Alomone antibody in rodent tissue.[20] Both bands were competed away by blocking peptide (Alomone Labs: www.alomone.com/p/anti-A2BA\%5fadenosine\%5freceptor\%5f(extracellular)/aar003/114). The band just smaller than $50 \mathrm{kDa}$ band was used for quantification as it was the most reproducible in our hands and was consistent with results by Vindeirinho et al.[20] 
Histology: The heart and lungs were removed en bloc under isoflurane anesthesia. Lungs were fixed with paraformaldehyde in the inflated state. Four-micron thick slices of paraffin-embedded, fixed whole-mount coronal sections of left and right lung were stained for hematoxylin and eosin. Extent of BOOP was quantified by assessing percentage of the cross sectional area of the lung involved at low power, morphology confirmed with high-resolution JPEG images, as we previously reported.[ 6] Histology consistent with BOOP (Masson bodies, inflammation, and young fibroblasts filling the distal airways and alveoli) was assessed with high power images. Using a scale developed for quantification of BOOP, [ 6], [21] we also performed grading of epithelial injury, fibrosis, and inflammatory changes (EFI) in the most severely affected areas of cross sectional lung images, each on a zero to three scale. The presence or absence of pulmonary vascular changes (thickening of intima or media or vascular drop out) and necrosis were noted in each image (Table 1). Two blinded reviewers graded all images. Average values were used for analysis.

Table 1. To quantify BOOP, we developed a grading scale for our studies[ 6 ] based on methods to quantify BOOP in human transplant patients.[21] This scale includes grading epithelial injury, fibrosis, and inflammatory changes, each on a scale from zero to three, and estimation of the percentage area of the lung exhibiting BOOP. Images were graded by two investigators blinded to the treatment group.

\begin{tabular}{|l|l|l|l|l|}
\hline $\begin{array}{l}\text { Histological } \\
\text { grading of BOOP }\end{array}$ & Normal & $\begin{array}{l}\text { 1 (mild) } \\
\text { Reactive epithelium } \\
\text { tintermittent } \\
\text { disruption of epithelial } \\
\text { layer }\end{array}$ & $\begin{array}{l}\text { 2 (moderate) } \\
\text { disruption and loss of } \\
\text { epithelium }\end{array}$ & 3 (severe) \\
\hline E (epithelial) & Young fibroblasts & $\begin{array}{l}\text { Intraluminal } \\
\text { fibromyxoid filling }\end{array}$ & Dense fibrosis \\
\hline F (fibrotic) & Normal & Yourgely \\
\hline I (inflammatory) & Normal & $\begin{array}{l}\text { Perivascular or } \\
\text { peribronchial cuffing } \\
\text { with mixed } \\
\text { inflammatory cells }\end{array}$ & $\begin{array}{l}\text { Moderate mixed } \\
\text { inflammatory } \\
\text { infiltration throughout } \\
\text { the lungs }\end{array}$ & $\begin{array}{l}\text { Severe infiltration } \\
\text { of mixed } \\
\text { inflammatory cells }\end{array}$ \\
\hline $\begin{array}{l}\text { Percent } \\
\text { involvement }\end{array}$ & $\begin{array}{l}\text { (from 0 to 100\% } \\
\text { in 10\% } \\
\text { increments) }\end{array}$ & \multicolumn{2}{l|}{} & \\
\hline
\end{tabular}

Statistical analysis: All analyses were not performed on all rats, as some (e.g., histological analysis and RNA extraction) were mutually exclusive. For each assay, a minimum of four, and typically five to eight, separate rats were studied per group. The group size is shown in the figure legends, figures, text, or table. Comparisons between ischemic and nonischemic lungs were performed using $t$ tests or rank sum tests followed by MannWhitney Rank Sum test when data were not normally distributed. Grouped data for three or more conditions were compared using one-way analysis of variance. When differences were found, a Holm-Sidak's post hoc test was employed. Statistical significance was assumed for $p<0.05$. All grouped data shown in figures are presented as means \pm standard error of the mean (SEM), means \pm standard deviation (SD), or medians and confidence intervals in the case of nonparametric data. 


\section{Results}

\section{Adenosine concentrations in BAL}

Representative HPLCs for quantification of adenosine concentrations appear in Figure 2a. Adenosine concentration values for control lungs of SD rats were not different than those from contralateral, nonischemic lungs from SD rats $(0.89 \pm 0.23 \mu \mathrm{M}$ vs. $0.59 \pm 0.09 ; n=4$ each). BAL from ischemic relative to contralateral lungs exhibited adenosine concentrations, which were increased approximately fourfold over those of contralateral lungs $24 \mathrm{~h}$ after PA ligation (Figure $2 \mathrm{a}$ and $2 \mathrm{~b}$ ).

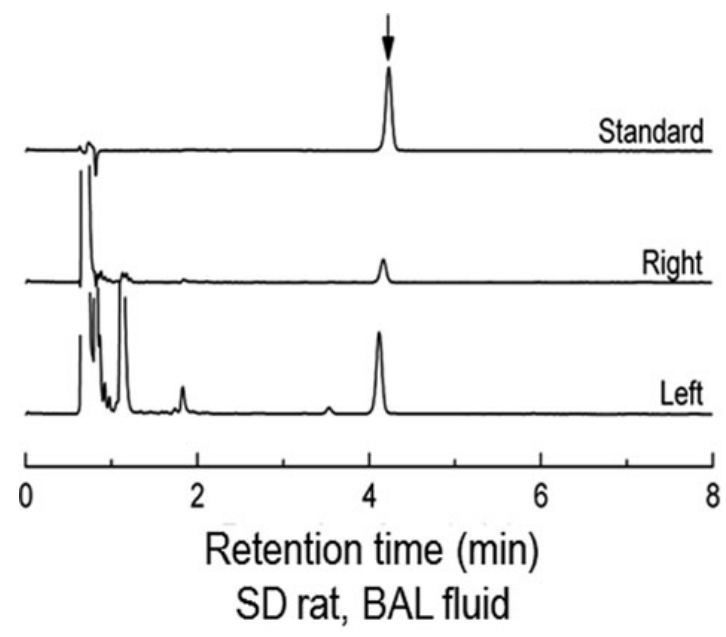

(a)

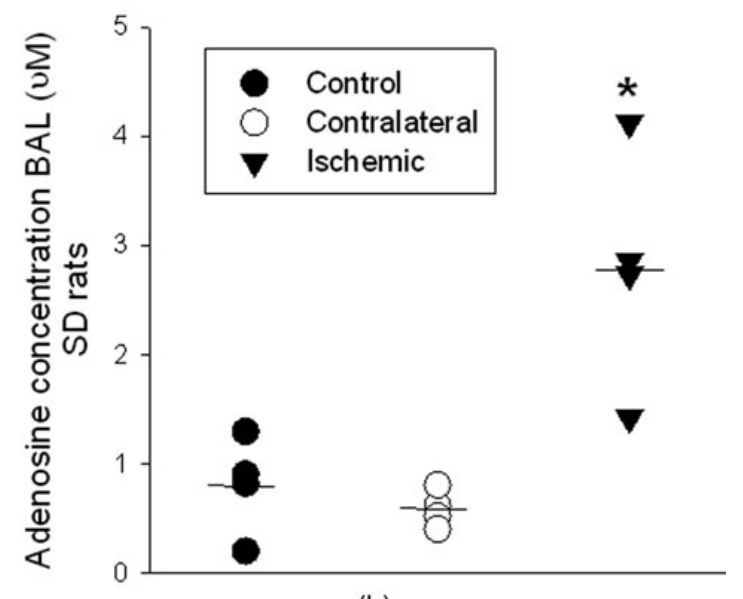

(b)

Graph: Figure 2. Adenosine concentrations were measured in BAL from four SD control rats or from isolated left and right lungs from four SD rats collected $24 \mathrm{~h}$ after left pulmonary artery ligation. Figure 2a shows representative chromatograms from an adenosine standard $(3 \mu \mathrm{M})$ and from BAL collected from the right and left lungs of ischemic/reperfused rats. The graph in $2 b$ shows individual values for samples. The concentration of adenosine was increased more than fourfold in BAL from ischemic lungs versus contralateral non-ischemic lungs $\left({ }^{*} p<0.008\right)$. Horizontal lines represent median values for each of the three groups.

\section{Adenosine receptor mRNA and protein expression}

Next we evaluated $A_{2 A} A R$ and $A_{2 B} A R$ mRNA expression in ischemic versus nonischemic lungs. Message for $A_{2 B} A R$ ( $n=17$ pairs, Mann-Whitney Rank Sum Test $p=0.03$ ) but not $A_{2 A} R(n=13$ pairs, Mann-Whitney Rank Sum Test $p=0.20$ ) was increased in ischemic lungs of SD rats 7 days after tie off of the left pulmonary artery (Figure 3). 


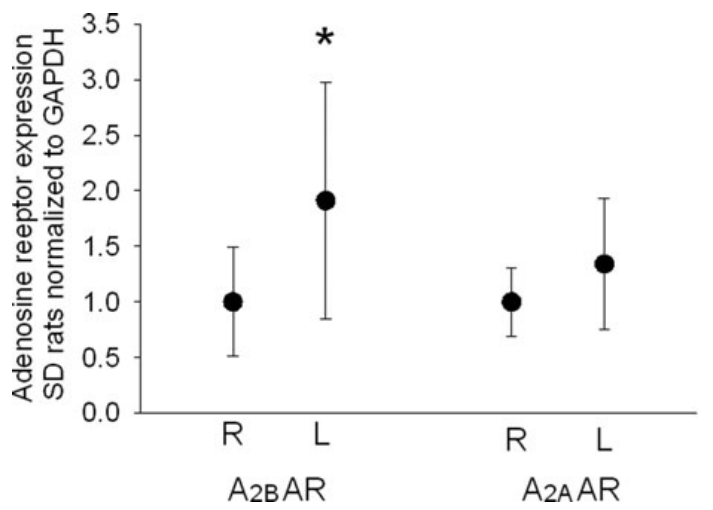

Graph: Figure 3. Graphic representation showing GAPDH normalized expression of A2BAR and A2AAR mRNA from ischemic ( $L=$ left) and nonischemic $(R=$ right) in 13 SD rats 7 days after left PA tie. The bars represent medians and bars show confidence intervals. A2BAR expression was greater in ischemic than nonischemic lungs $(p=0.03)$ while A2AAR was not different $(p=0.20)$.

Western blots of lung homogenates from ischemic left lungs of SD rats exhibited increased anti- $A_{2 B} A R$ immunoreactivity at two and seven days after unilateral ligation of the pulmonary arteries (Figures $4 a$ and 5 ). Similarly, SS rats had increased anti- $A_{2 B} A R$ immunoreactivity in ischemic versus contralateral non-ischemic lungs (Figure $4 \mathrm{~b}$ and 5 ). In contrast, anti- $\mathrm{A}_{2} \mathrm{AR}$ immunoreactivity from the same rats was not different between ischemic and nonischemic lungs (Figure $4 c ; n=9$ pairs, $p=0.8$ ). In a second lung injury model involving unilateral warm ischemia of the lung for one hour followed by in vivo reperfusion for three additional hours, $A_{2 B} A R$ protein density normalized to beta actin was also increased in ischemic relative to contralateral lungs ( $n=8$ pairs; $125 \pm 10$ vs. $90 \pm 12, p<0.05$; data not shown). 


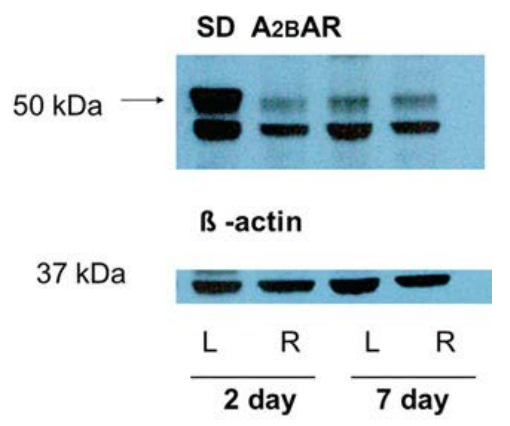

(a)

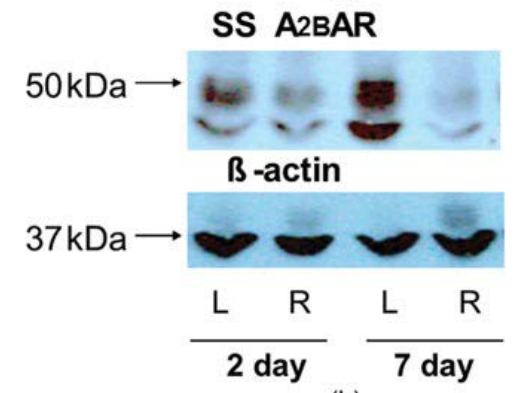

(b)

SD A2AAR
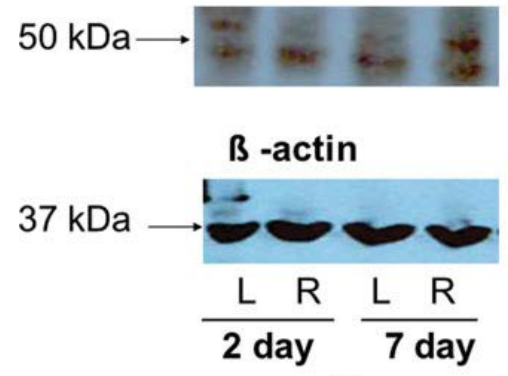

(c)

Graph: Figure 4. 4a shows representative Western blots of homogenates from ischemic ( $L=l$ left) and contralateral $(R=$ right) lungs from SD rats harvested either 2 or 7 days after pulmonary artery ligation probed with the A2BAR antibody. A prominent band under $50 \mathrm{kDa}$ was observed in all of the studies along with a secondary band near $37 \mathrm{kDa}$ in some instances. The larger band just under $50 \mathrm{kDa}$ was used for quantification. After quantification of A2BAR protein, membranes were probed for beta actin, which was not different in left and right lungs. Beta actin was used to normalize A2BAR immunoreactivity for protein loading. Ischemic left lungs exhibited increased A2BAR immunoreactivity compared to their control right lung counterparts. 4b. Representative images from studies similar to those in Figure 4a except that homogenates were obtained from lungs of SS rather than SD rats. Again, increased A2BAR immunoreactivity in ischemic left compared to contralateral right lungs was observed seven days after ischemia. 4c. Representative Western blots from the same samples as Figure 4a (SD rats) probed with primary A2AAR antibodies. The band between 37 and $50 \mathrm{kDa}$ was quantified.[20] Bands were less consistent than those probed A2BAR antibody and no differences in A2AAR immunoreactivity between ischemic and contralateral lungs were observed. 


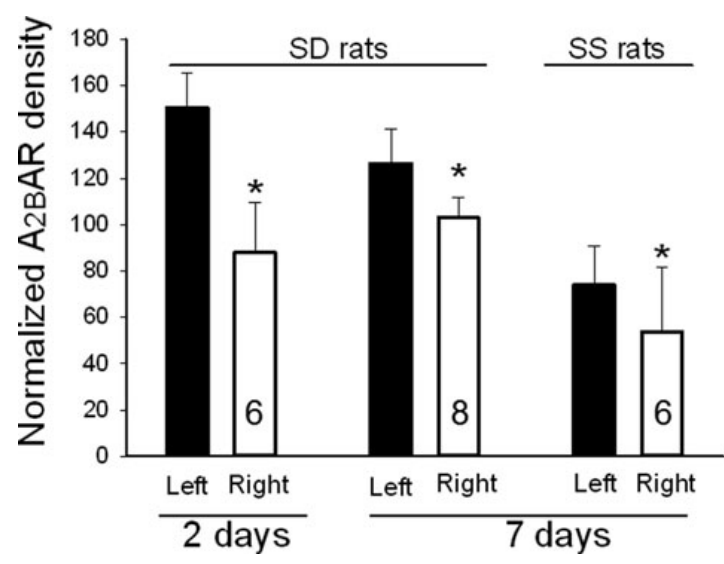

Graph: Figure 5. Graph shows averaged density of A2BAR immunoreactivity normalized to beta actin in lung homogenates from left and right lungs of SD rats at $2(n=6)$ and 7 days $(n=8)$ after ischemia, and in SS rats seven days $(n=6)$ after the same ischemic injury. These are aggregate data including those examples shown in Figure 4. "N's in the bars represent the number of paired samples on each group. In each case, the density of immunoreactivity is increased in ischemic left over contralateral right lungs with $p<0.005$ by paired t test. Bars represent standard deviation.

Expression of the $A_{2 B} A R$ is reported to be modulated by miRNAs 27a-3p, 27b-3p, and 128-3p.[14] RT-qPCR data normalized for an internal miRNA, miR191-5p demonstrated decreased 27a and 27b miRNA in ischemic versus nonischemic lung tissue at 7 days (Table 2). Normalization for the spiked sequence UniSP6 also showed decreased 27a-3p miRNA in ischemic lungs compared to contralateral controls. There was no difference in miR191-5p expression when normalized to UniSP6. These results confirm a decrease in miR27a-3p after ischemia.

Table 2. qPCR and p-values for miR27b-3p, miR128-3p, miR27a-3p, and miR191-5p normalized to either 191-5p or UniSP6 for left and right lungs harvested 7 days after ischemia. Once normalized for 191-5p or UniSP6, qPCR values for right lung (nonischemic) were set at 1 , the left lung values expressed as a fraction of the right. Pvalues are different in left and right lungs for miR27b-3p and miR27a-3p when qPCR values are normalized to miR191, and for miR27a when normalized for UniSP6.

\begin{tabular}{|l|l|l|l|l|}
\hline & Normalized by & Nonischemic $R(n=8)$ mean \pm SD & Ischemic $L(n=8)$ mean \pm SD & Sig by t test \\
\hline miR 27b-3p & miR191 & $1 \pm 0.11$ & $0.82 \pm 0.17$ & ${ }^{*} \mathrm{P}=0.021$ \\
\hline miR 128-3p & miR191 & $1 \pm 0.28$ & $0.68 \pm 0.26$ & $\mathrm{P}=0.976$ \\
\hline miR 27a & miR191 & $1 \pm 0.17$ & $0.66 \pm 0.07$ & ${ }^{*} \mathrm{P}=0.000135$ \\
\hline miR191-5p & SP6 & $1 \pm 0.12$ & $1.04 \pm 0.17$ & $\mathrm{P}=0.610$ \\
\hline miR 27b-3p & SP6 & $1 \pm 0.08$ & $0.86 \pm 0.23$ & $\mathrm{P}=0.113$ \\
\hline miR 128-3p & SP6 & $1 \pm 0.09$ & $0.97 \pm 0.11$ & $\mathrm{P}=0.551$ \\
\hline miR 27a & SP6 & $1 \pm 0.1$ & $0.7 \pm 0.13$ & ${ }^{*} \mathrm{P}=0.00014$ \\
\hline
\end{tabular}

\section{Histology}

We have reported that unilateral ischemia of the lung induced by pulmonary artery tie results in BOOP and inflammatory changes seven days after surgery in SD rats.[ 6] To begin to test the contribution of $A_{2 B} A R$ expression to the development of BOOP, we quantified percent BOOP in ischemic lungs of a genetically modified rat strain with deletions of $A_{2 B} A R$ relative to the background strain (Dahl SS). [22] Representative images of cross sections of whole mount ischemic lungs appear in Figure 6(a-c). We observed more lung involvement by BOOP in rats genetically modified by Adora2b disruption (Table 3 and Figure $6 a-d)$. Additional studies to assess for injury were completed. Higher epithelial and inflammatory but not fibrotic scores were assigned to images of 
lung cross sections from Adora2b disrupted rats (Table 3). Pulmonary vascular changes (thickened media or intima) were not different between Adora2b mutant rats and background controls (Table 3). Scattered pockets of necrosis were observed in one of five and one of four cross sectional areas, respectively, of a SS control rat and an Adora2b rat (also not different and not shown).

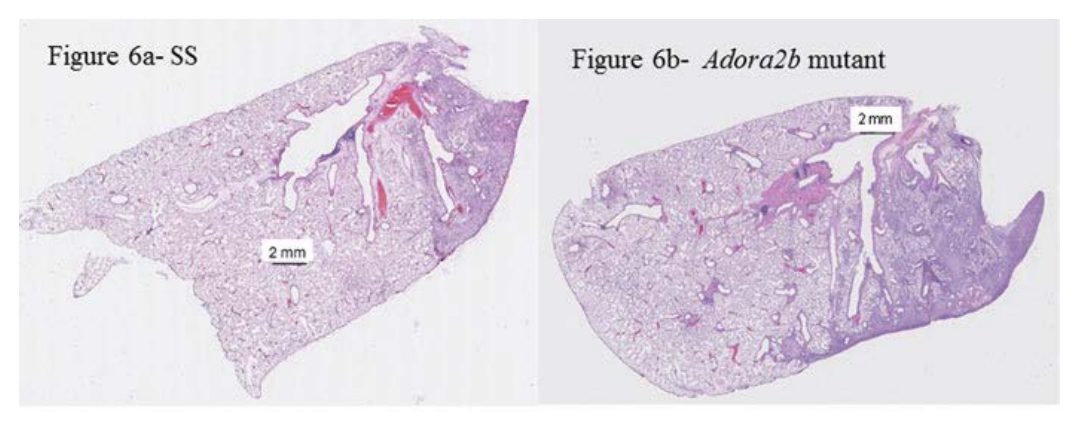

Figure 6c- SS

Figure 6d-Adora2b mutant
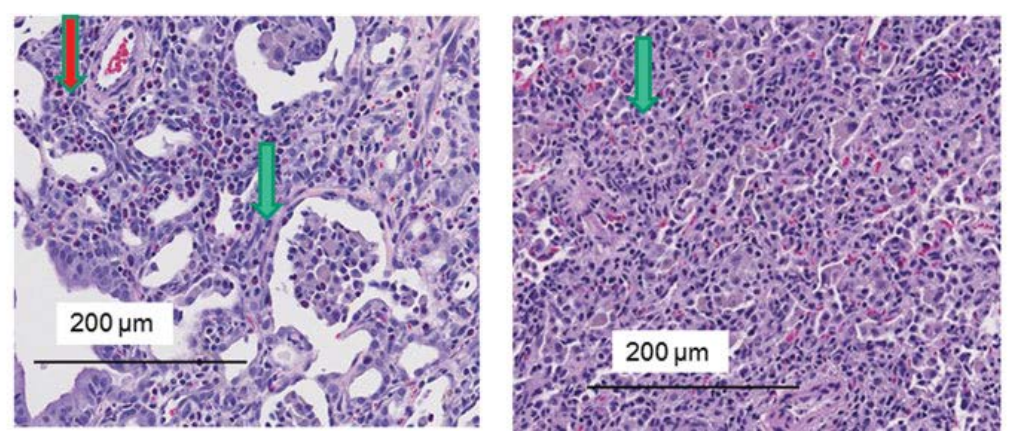

Graph: Figure 6. Representative histological images from lung cross sections from SS (a and c) and SS-AdorA2b mutant rats ( $b$ and $d$ ) seven days after ischemia. Low power ( $a$ and $b$ ) shows areas of increased cellularity, which were consistent with BOOP under high power magnification ( $c$ and $d$ ). The area of BOOP is modestly larger in the image from lungs of mutant rats. The green arrows in the magnified images ( $c$ and $d$ ) show typical epithelial changes, whereas the red arrow shows perivascular inflammation (c). In some images from mutants (not shown), areas of inflammation outside sections showing significant epithelioid changes were observed.

Table 3. Mean and SEM as well as median and $95 \%$ confidence interval values for epithelial, inflammation, and fibrosis changes in images from lungs scored by investigators blinded to the treatment group. Epithelial and inflammatory changes were different in ischemic lungs of SS and SS-Adora2b mutant rats while fibrotic changes were not. Confidence intervals: $\mathrm{Cl}$ and standard error of the mean: SEM.

\begin{tabular}{|c|l|l|l|}
\hline & Dahl SS $(n=5)$ & A2bAR knock out $(n=4)$ & P-value relative to Dahl SS \\
\hline \%BOOP & & & \\
\hline Mean/median & $18 / 25$ & $60 / 67.5$ & $0.02^{*}$ \\
\hline SEM/Cl & $3.4 / 19$ & $10 / 32$ & \\
\hline Epithelial & & & \\
\hline Mean/median & $1.08 / 1.00$ & $1.6 / 2.0$ & $0.031^{*}$ \\
\hline SEM/Cl & $0.15 / 0.3$ & $0.18 / 0.39$ & \\
\hline Inflammation & & & \\
\hline Mean/median & $1.5 / 2.0$ & $2.43 / 2.0$ & $0.048^{*}$ \\
\hline SEM/Cl & $0.19 / 0.43$ & $0.21 / 0.44$ & \\
\hline Fibrosis & & & \\
\hline Mean/median & $0.79 / 1.0$ & $1.32 / 2.0$ & $0.5 \mathrm{~ns}$ \\
\hline
\end{tabular}




\begin{tabular}{|c|l|l|l|}
\hline $\mathrm{SEM} / \mathrm{Cl}$ & $0.19 / 0.42$ & $0.26 / 0.55$ & \\
\hline Vascular changes & & & \\
\hline Mean/median & $0.2 / 0.0$ & $0.5 / 0.5$ & $0.4 \mathrm{~ns}$ \\
\hline $\mathrm{SEM} / \mathrm{Cl}$ & $0.5 / 0.55$ & $0.29 / 0.92$ & \\
\hline
\end{tabular}

\section{Discussion}

We provide compelling evidence that expression of $A_{2 B} A R$ mRNA and/or protein is increased in the lungs of two different rat strains (SD and SS) for at least seven days following ischemia by either isolated pulmonary artery ligation or hilar ligation (no ventilation or perfusion) with ischemia/reperfusion. Coincident with increased $A_{2 B} A R$ expression, a candidate miRNA for at least one of three sequences reported to suppress AdorA2BA transcription, miR27a, is decreased. Physiologically, we observed increased adenosine levels in bronchoalveolar lavage fluid and increased BOOP in ischemic lungs from rat strains that contain mutations in Adora2b. Collectively, these findings indicate that adenosine signaling via the $A_{2 B} A R$ may mediate a protective role in ischemia-induced BOOP.

Adenosine and its receptors have an established modulatory role during acute organ injury as well as during tissue remodeling that occur during chronic inflammatory states. Extracellular adenosine elicits biological effects through activation of four $G$-coupled protein adenosine receptors ( $A_{1} A R, A_{2 A} A R, A_{2 B} A R$, and $\left.A_{3} A R\right)$. [23] In the lung, $A_{2 B} A R$ expression has been reported in bronchial epithelial cells in both medium and large airways, pulmonary vascular cells, and alveolar macrophages. [24], [25] A major site of $A_{2 B} A R$ translation is the type II alveolar epithelial cell.[24] Endogenous adenosine released following cell injury has been reported to protect against I/R injury in lungs.[26] Further, protection from I/ $R$ in isolated perfused rabbit lungs is achieved with treatment by agonists for $A_{1}, A_{2 A}$, or $A_{3}$ adenosine receptors.[27] In these models, decreased elaboration of the proinflammatory cytokine, TNF- $\alpha$, and decreased neutrophil sequestration are postulated to contribute to the overall improvement in pulmonary function, a signaling pathway triggered by adenosine receptor binding. Koeppen et al. report that $A_{2 B} A R$ activation requires higher ligand concentrations as compared to other adenosine receptors. [ 7] Given the abundance of adenosine during I/R and induction of $A_{2 B} A R$ expression, signaling by this pathway likely promotes homeostasis. We propose that this compensatory mechanism serves an important role to protect the lung tissue from remodeling to a state of BOOP.

While some studies demonstrate a protective role by $A_{2 A} A R$ signaling during lung injury[27], [28], [29], [30] we did not detect changes in expression of this important adenosine receptor subtype in our studies following unilateral lung ischemia. $A_{2 B} A R$ expression, however, increases over time after ischemia and I/R (Figures 3 and 5). This result implicates $A_{2 B} A R$ expression as an inducible and adaptive response to ischemia. Notably, a binding site for hypoxia-inducible factor-1 $\alpha$ (HIF-1 $\alpha$ ) exists within the $A_{2 B} A R$ promoter.[31], [32], [33]

The role of $A_{2 B} A R$ signaling in all cause injury is controversial. On the side of promoting injury, $A_{2 B} A R$ stimulation has been reported to promote the development of $\mathrm{BO}$ in a heterotopic tracheal implantation mouse model by inhibiting CD4+/CD25+/Foxp3+ regulatory T cell infiltration. [ 9] In the presence of hypoxia, $A_{2 B} A R$ activation synergistically activates human fibroblasts, presumably leading to fibrosis.[32] Activation of $A_{2 B} A R$ in smooth bronchial muscle cells enhances release of IL- 6 and monocyte chemotactic protein (MCP-1).[34] $A_{2 B} A R$ transcriptionally activates HIF-1 $\alpha$ and hence favors an ischemic response.[ 7] Most germane to the present studies, disruption of the $A_{2 b}$ adenosine receptor in the rats used for our studies is associated with increased body weight, delayed glucose clearance, modestly elevated systemic blood pressures with age, and reduced cytokine production after challenge with lipopolysaccharide.[22] These data would suggest increased inflammatory responses evoked by ischemia in our genetically modified rats are either mediated by different cytokines than those evoked by LPS, or is driven largely by noncytokine dependent signaling. 
Several other models demonstrate protection with $A_{2 B} A R$ activation. Pharmacologic inhibition and/or genetic elimination of $A_{2 B} A R$ increases murine endotoxin-induced lung injury.[12] In a murine model of LPS-induced lung injury, activation of $A_{2 B} A R$ on pulmonary endothelial cells decreases microvascular permeability and neutrophil migration into alveolar spaces.[35] $A_{2 B} A R$-deficient mice enjoy greater survival than their wild-type counterparts in polymicrobial sepsis.[36] $A_{2 B} A R$ signaling enhances amiloride-sensitive fluid transport and elevation of pulmonary cAMP levels following ventilator associated lung injury in mice, suggesting that $A_{2 B} A R$ agonist treatment protects by facilitating fluid resorption from the lungs.[10] Perhaps most applicable to our data, ischemia reperfusion injury to the liver in mice is associated with robust induction of $A_{2 B} A R$ transcript and protein.[37] Mice with AdorA2BA-deletion exhibited increased sensitivity to injury. Finally, treatment of wildtype mice with an $A_{2 B} A R$-selective antagonist resulted in worsened liver injury, whereas $A_{2 B} A R$-agonist treatment attenuated hepatic injury in wild type, but not in AdorA2BA-/- mice. Our data demonstrating increased BOOP 7 days after ischemia in AdorA2BA mutant rats add additional credence to a protective role for the adenosine/ $A_{2 B} A R$ signaling axis after ischemia. To our knowledge, this is the first report that $A_{2 B} A R$ signaling is protective from BOOP after ischemic injury in the lung.

Micro RNA (miRNA) are short (20-30 nucleotide) translational regulator sequences encoded in the eukaryotic DNA genome. Their usual function is to bind complementary single-stranded mRNA sequences undergoing translation by ribosomal complexes. When this binding occurs, the ribosomal translation is halted, resulting in an ineffective protein product. At least two miRNAs have been reported to modulate posttranscriptional expression of $A_{2 B} A R$ in a model of mouse colitis: miR27b, miR128a.[14] These miRNAs decrease $A_{2 B} A R$ translation in colonocytes from this model. Furthermore, miR27b and miR128a transcription was suppressed by TNF- $\alpha$.[14] Our data demonstrate decreases in miR27a and 27b, consistent with the hypothesis that these miRNA contribute to post-transcriptional increase of $A_{2 B} A R$ after injury. Further studies will help determine the factors/cytokines that are induced by ischemia to regulate miRNA expression, especially downregulation of miR27a.

There are limitations to our studies. First, the cellular sources of increased $A_{2 B} A R$ expression in ischemic lungs remain to be determined. Unfortunately, attempts at immunohistochemical localization were unsuccessful due to interference by background staining. Second, the specificity of commercially available antibodies for adenosine receptors has been questioned raising concerns regarding accuracy of assessing changes in adenosine receptor protein expression by immunological approaches. Nevertheless, we followed procedures utilized successfully in several previously published reports.[ 7], [20], [36], [37] With this in mind, it was important that changes in $A_{2 B} A R$ protein expression in lung tissue observed in our studies by Western immunoblotting were paralleled by changes in mRNA expression. Although we did not obtain evidence for increased $A_{2 A} A R$ expression, our data do not exclude a role for adenosine signaling through these or other adenosine receptor subtype during ischemia-induced BOOP. They do suggest, however, that increases in $A_{2 A} A R$ expression and crossreactivity with $A 2 b R$ do not account for the increases in $A 2 b R$ protein we observed in ischemic lungs. Lastly, the effects seen may be due to other factors besides tissue oxidative state (e.g., resulting from hemostasis in the pulmonary circulation and resultant proinflammatory changes in the endothelium).

Our work provides strong justification for additional studies. If $A_{2 B} A R$ signaling protects from ischemic lung injury, then this axis affords a target to diminish the morbidity and mortality resulting from lung transplantation. [ 1], [ 2] Given the 50\% 5-year mortality from BO in transplanted lungs and the extensive waiting lists for those with end-stage lung disease,[38], [39], [40] interventions that may extend the survival of transplanted lung recipients by even a few years with good functional capacity are highly desirable. Successful therapies will most likely be based on countering mechanisms of injury or enhancing protective signaling pathways. Our work provides justification for further studies of $A_{2 B} A R$-mediated events as a strategy to enhance protection of ischemic lungs. 


\section{Acknowledgments}

The authors appreciate the excellent assistance in surgical procedures, lavage, and western blots of Ying Gao. Jayashree Narayanan assisted with manuscript preparation, editing, and RNA studies. Dr. Jacek Zielonka, Research Director Free Radical Research Center Department of Biophysics provided HPLC services to quantify adenosine levels in bronchoalveolar lavage. MeiYing Yang assisted with RNA studies.

\section{Declaration of interest}

None of the authors has derived personal support and has not been involved with any organizations with financial interest in the conduct of this research.

\section{Funding}

Dr. Densmore received support from the Clinical \& Translational Science Institute of Southeastern Wisconsin [CTSA Grant UL1RR031973] and Advancing a Healthier Wisconsin. Dr. Jacobs was supported in this work by the National Institutes of Health [HL116530] and the Department of Veterans Affairs [BX001681]. Dr. Audi was supported by the Clinical \& Translational Science Institute of Southeastern Wisconsin [CTSA Grant UL1RR031973] and the National Institutes of Health [R15HL129209]. Dr. Auchampach was supported by the National Institutes of Health [HL077707, HL111392]. The described SS-Adora2b mutant rat strain was created with support by the National Institutes of Health [HL101681] to Drs. Geurts and Dwinell as part of a rat genome project completed at the Medical College of Wisconsin, which may someday receive royalties for mutant rat strains. Dr. Medhora was supported by the National Institutes of Health/National Institute of Allergy and Infectious Diseases (NIAID) Al81294, Al101898, and Al107305.

\section{Footnotes}

1 Color versions of one or more of the figures in the article can be found online at www.tandfonline.com/ielu.

\section{References}

1Orens JB, Garrity ER, Jr. General overview of lung transplantation and review of organ allocation. Proc Am Thorac Soc. 2009;6:13-19.

2 Boehler A, Kesten S, Weder W, Speich R. Bronchiolitis obliterans after lung transplantation: a review. Chest. 1998;114:1411-1426.

3 Burton CM, Iversen $M$, Carlsen J, Andersen CB. Interstitial inflammatory lesions of the pulmonary allograft: a retrospective analysis of 2697 transbronchial biopsies. Transplantation. 2008;86:811-819.

4 Chaparro C, Chamberlain D, Maurer J, Winton T, Dehoyos A, Kesten S. Bronchiolitis obliterans organizing pneumonia (BOOP) in lung transplant recipients. Chest. 1996;110:1150-1154.

5 Pettersson GB, Budev M. The role of ischemia in postlung transplantation complications. Curr Opin Organ Transplant. 2010;15:549-551.

6 Densmore JC, Jeziorczak PM, Clough AV, Pritchard KA, Jr., Cummens B, Medhora M, et al. Rattus model utilizing selective pulmonary ischemia induces bronchiolitis obliterans organizing pneumonia. Shock. 2013;39:271- 277.

7 Koeppen M, Eckle T, Eltzschig HK. Interplay of hypoxia and A2B adenosine receptors in tissue protection. Adv Pharmacol. 2011;61:145-186.

8 Sun CX, Zhong H, Mohsenin A, Morschl E, Chunn JL, Molina JG, et al. Role of A2B adenosine receptor signaling in adenosine-dependent pulmonary inflammation and injury. J Clin Invest. 2006;116:2173-2182. 
9 Zhao Y, LaPar DJ, Steidle J, Emaminia A, Kron IL, Ailawadi G, et al. Adenosine signaling via the adenosine $2 B$ receptor is involved in bronchiolitis obliterans development. J Heart Lung Transplant. 2010;29:14051414.

Eckle T, Grenz A, Laucher S, Eltzschig HK. A2B adenosine receptor signaling attenuates acute lung injury by enhancing alveolar fluid clearance in mice. J Clin Invest. 2008;118:3301-3315.

Hoegl S, Brodsky KS, Blackburn MR, Karmouty-Quintana H, Zwissler B, Eltzschig HK. Alveolar epithelial A2B adenosine receptors in pulmonary protection during acute lung injury. J Immunol. 2015;195:1815-1824.

Schingnitz U, Hartmann K, Macmanus CF, Eckle T, Zug S, Colgan SP, et al. Signaling through the A2B adenosine receptor dampens endotoxin-induced acute lung injury. J Immunol. 2010;184:5271-5279.

Rolland-Turner M, Goretti E, Bousquenaud M, Léonard F, Nicolas C, Zhang L, et al. Adenosine stimulates the migration of human endothelial progenitor cells. Role of CXCR4 and microRNA-150. PLoS One. 2013;8:e54135.

Kolachala VL, Wang L, Obertone TS, Prasad M, Yan Y, Dalmasso G, et al. Adenosine 2B receptor expression is post-transcriptionally regulated by microRNA. J Biol Chem. 2010;285:18184-18190.

Torres-Marquez ME, Esparza-Garrido RR, Sinnett-Smith J, Rozengurt E. Saline stress modulates mir-27a, mir-103 and mir135 in 3T3-PKD-1 cells (802.15). FASEB J. 2014;28:802.15.

Geurts AM, Cost GJ, Freyvert Y, Zeitler B, Miller JC, Choi VM, et al. Knockout rats via embryo microinjection of zinc-finger nucleases. Science. 2009;325:433-435.

Geurts AM, Cost GJ, Remy S, Cui X, Tesson L, Usal C, et al. Generation of gene-specific mutated rats using zincfinger nucleases. Methods Mol Biol. 2010;597:211-225.

Ali I, Gruenloh S, Gao Y, Clough A, Falck JR, Medhora M, et al. Protection by 20-5,14-HEDGE against surgically induced ischemia reperfusion lung injury in rats. Ann Thorac Surg. 2012;93:282-288.

Driver AG, Kukoly CA, Ali S, Mustafa SJ. Adenosine in bronchoalveolar lavage fluid in asthma. Am Rev Respir Dis. 1993;148:91-97.

Vindeirinho J, Costa GN, Correia MB, Cavadas C, Santos PF. Effect of diabetes/hyperglycemia on the rat retinal adenosinergic system. PLoS One. 2013;8:e67499.

Martinu T, Howell DN, Davis RD, Steele MP, Palmer SM. Pathologic correlates of bronchiolitis obliterans syndrome in pulmonary retransplant recipients. Chest. 2006;129:1016-1023.

Nayak S, Khan MA, Wan TC, Pei H, Linden J, Dwinell MR, et al. Characterization of Dahl salt-sensitive rats with genetic disruption of the $A 2 B$ adenosine receptor gene: implications for $A 2 B$ adenosine receptor signaling during hypertension. Purinergic Signal. 2015 Dec;11:519- 531.

Idzko M, Ferrari D, Riegel AK, Eltzschig HK. Extracellular nucleotide and nucleoside signaling in vascular and blood disease. Blood. 2014;124:1029-1037.

Cagnina RE, Ramos SI, Marshall MA, Wang G, Frazier CR, Linden J. Adenosine A2B receptors are highly expressed on murine type II alveolar epithelial cells. Am J Physiol Lung Cell Mol Physiol. 2009;297:L467- L474.

Clancy JP, Ruiz FE, Sorscher EJ. Adenosine and its nucleotides activate wild-type and R117H CFTR through an A2B receptor-coupled pathway. Am J Physiol. 1999;276:C361-C369.

Gazoni LM, Walters DM, Unger EB, Linden J, Kron IL, Laubach VE. Activation of A1, A2A, or A3 adenosine receptors attenuates lung ischemia-reperfusion injury. J Thorac Cardiovasc Surg. 2010;140:440-446.

Gazoni LM, Laubach VE, Mulloy DP, Bellizzi A, Unger EB, Linden J, et al. Additive protection against lung ischemiareperfusion injury by adenosine $A 2 A$ receptor activation before procurement and during reperfusion. $J$ Thorac Cardiovasc Surg. 2008;135:156-165.

Folkesson HG, Kuzenko SR, Lipson DA, Matthay MA, Simmons MA. The adenosine 2A receptor agonist GW328267C improves lung function after acute lung injury in rats. Am J Physiol Lung Cell Mol Physiol. 2012;303:L259-L271.

Impellizzeri D, Di Paola R, Esposito E, Mazzon E, Paterniti I, Melani A, et al. CGS 21680, an agonist of the adenosine (A2A) receptor, decreases acute lung inflammation. Eur J Pharmacol. 2011;668:305-316. 
LaPar DJ, Laubach VE, Emaminia A, Crosby IK, Hajzus VA, Sharma AK, et al. Pretreatment strategy with adenosine A2A receptor agonist attenuates reperfusion injury in a preclinical porcine lung transplantation model. J Thorac Cardiovasc Surg. 2011;142:887-894.

Kong T, Westerman KA, Faigle M, Eltzschig HK, Colgan SP. HIF-dependent induction of adenosine A2B receptor in hypoxia. FASEB J. 2006;20:2242-2250.

Zhong $H$, Belardinelli L, Maa T, Zeng D. Synergy between A2B adenosine receptors and hypoxia in activating human lung fibroblasts. Am J Respir Cell Mol Biol. 2005;32:2-8.

Eckle T, Kewley EM, Brodsky KS, Tak E, Bonney S, Gobel M, et al. Identification of hypoxia-inducible factor HIF-1A as transcriptional regulator of the $A 2 B$ adenosine receptor during acute lung injury. J Immunol. 2014;192:1249-1256.

Zhong H, Belardinelli L, Maa T, Feoktistov I, Biaggioni I, Zeng D. A(2B) adenosine receptors increase cytokine release by bronchial smooth muscle cells. Am J Respir Cell Mol Biol. 2004;30:118-125.

Konrad FM, Witte E, Vollmer I, Stark S, Reutershan J. Adenosine receptor A2b on hematopoietic cells mediates LPS-induced migration of PMNs into the lung interstitium. Am J Physiol Lung Cell Mol Physiol. 2012;303:L425-L438.

Csoka B, Nemeth ZH, Rosenberger P, Eltzschig HK, Spolarics Z, Pacher $P$, et al. A2B adenosine receptors protect against sepsis-induced mortality by dampening excessive inflammation. J Immunol. 2010;185:542-550.

Zimmerman MA, Grenz A, Tak E, Kaplan M, Ridyard D, Brodsky KS, et al. Signaling through hepatocellular A2B adenosine receptors dampens ischemia and reperfusion injury of the liver. Proc Natl Acad Sci U SA. 2013;110:12012-12017.

Cypel M, Yeung JC, Keshavjee S. Novel approaches to expanding the lung donor pool: donation after cardiac death and ex vivo conditioning. Clin Chest Med. 2011;32:233-244.

Davis SQ, Garrity ER, Jr. Organ allocation in lung transplant. Chest. 2007;132:1646-1651.

Verleden GM. Bronchiolitis obliterans syndrome after lung transplantation: medical treatment. Monaldi Arch Chest Dis. 2000;55:140-145. 